\title{
O enfrentamento dos familiares cuidadores de adoecidos em cuidados paliativos oncológicos domiciliares diante dos estressores do cuidado
}

\author{
Coping of the family caregivers of sick people in home oncological palliative care against \\ of care stressors \\ El afrontamiento de cuidadores familiares de personas enfermas en cuidados paliativos \\ oncológicos domiciliarios frente a los factores estresantes del cuidado
}

Antônio Corrêa Marques Neto ${ }^{1 *}$, Jamil Michel Miranda do Vale ${ }^{1}$, Lucialba Maria Silva dos Santos ${ }^{1}$, Mary Elizabeth de Santana'.

\section{RESUMO}

Objetivo: Identificar os principais fatores de estresse do familiar cuidador de adoecidos em cuidados paliativos oncológicos domiciliares. Métodos: Trata-se de pesquisa descritiva com abordagem qualitativa, realizada com 10 familiares cuidadores de adoecidos pelo câncer em cuidados paliativos oncológicos, vinculados ao Serviço de Assistência Domiciliar em um hospital de referência oncológica. Foi realizada observação das visitas domiciliares e retorno para realização de entrevista semiestruturada mediante roteiro de questões abertas. Os materiais gerados foram submetidos à Análise de Conteúdo Temático de Bardin. $O$ estudo foi aprovado por Comitê de Ética em Pesquisa. Resultados: A partir da análise dos dados, emergiram duas categorias temáticas e suas respectivas subcategorias: Estressores do cuidado: do amor à dor, com as subcategorias: O cuidar como sinônimo de amor e compromisso; e Estressores do cuidado: adoecimento físico e psicológico. Segunda categoria: Superando os limites do estresse: estratégias de enfrentamento. Conclusão: Conclui-se que o cuidado é desenvolvido pelas familiares cuidadoras com responsabilidade, amor e compromisso, sendo que os principais estressores identificados, estão relacionados ao adoecimento físico e abalo psicológico. Algumas cuidadoras buscam superar o estresse através de diversas estratégias de enfrentamento, outras não conseguem fazê-lo, pois não recebem orientações.

Palavras-Chave: Enfermagem oncológica, Cuidados paliativos, Cuidadores.

\section{ABSTRACT}

Objective: To identify the main stress factors of the family caregiver of sick in home oncologic palliative care. Methods: This is a descriptive research with a qualitative approach, conducted with 10 family caregivers of cancer patients in palliative cancer care, linked to the Home Care Service in a oncologic referral hospital. Observation of home visits and return to perform of semi-structured interview was made through a script of open questions. The generated materials were submitted to Bardin Thematic Content Analysis. The study was approved by the Research Ethics Committee. Results: From the data analysis, two thematic categories and their respective subcategories emerged: Care stressors: from love to pain, with the subcategories: Care as a synonym of love and commitment; and Stressors of care: physical and psychological illness. Second category: Overcoming the limits of stress: coping strategies. Conclusion: It is concluded that care is developed by family caregivers with responsibility, love and commitment, and the main stressors identified are related to physical illness and psychological distress. Some caregivers seek to overcome stress through various coping strategies, others are unable to do so because they do not receive guidance.

Keywords: Oncology nursing, Palliative care, Caregivers.

${ }^{1}$ Universidade Federal do Pará (UFPA), Belém-PA. *E-mail: nicolelameira@gmail.com 


\section{RESUMEN}

Objetivo: Identificar los principales factores de estrés de los cuidadores familiares de personas enfermas en cuidados paliativos oncológicos domiciliarios. Métodos: Esta es una investigación descriptiva con un enfoque cualitativo, realizada con 10 cuidadores familiares de pacientes con cáncer en cuidados paliativos oncológicos, vinculados al Servicio de la Atención Domiciliaria en un hospital de referencia oncológica. Se realizó la observación de las visitas domiciliarias y el regreso a entrevista semiestructurada a través de un guión de preguntas abiertas. Los materiales generados se enviaron a Análisis de Contenido Temático de Bardin. El estudio fue aprobado por el Comité de Ética en Investigación. Resultados: Del análisis de datos surgieron dos categorías temáticas y sus respectivas subcategorías: Estresores de cuidado: del amor al dolor, con las subcategorías: Cuidado como sinónimo de amor y compromiso; y Estresores de cuidado: enfermedad física y psicológica. Segunda categoría: Superando los límites del estrés: estrategias de afrontamiento. Conclusión: Se concluye que el cuidado es desarrollado por los cuidadores familiares con responsabilidad, amor y compromiso, y los principales factores estresantes identificados están relacionados con enfermedades físicas y trastornos psicológicos. Algunos cuidadores buscan superar el estrés mediante diversas estrategias de afrontamiento, otros no pueden hacerlo porque no reciben orientación.

Palabras clave: Enfermería oncológica, Cuidados paliativos, Cuidadores.

\section{INTRODUÇÃO}

Globalmente, sabe-se que o câncer é uma das doenças preditivas aos cuidados paliativos (CP), apesar de no Brasil, outras doenças não malignas surgirem dentro desta modalidade (PHILIP RR, et al., 2018). Segundo a World Health Organization (2018) ocorrerão aproximadamente 18 milhões de novos casos de câncer em todo mundo. No Brasil, serão mais de 600 mil casos novos anualmente (INCA, 2017b), levando cada vez mais pessoas aos cuidados paliativos (CP).

Quando abordamos a condição do câncer em estágio avançado, considerado incurável e tratado como uma doença crônica, exige-se a necessidade de cuidadores familiares (CFs), visto que, durante todo o tratamento e no final da vida, pacientes e cuidadores experimentam notável sofrimento psicológico, necessitando assim, dos cuidados paliativos, apoio e suporte excepcional (JACOBS JM, et al., 2017).

Estes cuidadores familiares, no domicilio, administram grande variedade de responsabilidades em sua vida e na vida de quem cuida. Eles exercem atividades que parecem vitais para a continuidade da sobrevivência dos pacientes em finitude, rastreando e controlando sinais e sintomas que surgem, administrando medicamentos, organizando as consultas e agendamentos com demais profissionais de saúde; prestam apoio emocional e espiritual, além de realizar as atividades domesticas e financiar gastos.

Com o passar do tempo, tendem a sentirem-se estressados com as atividades, ficando então propensos à depressão, ansiedade e demais problemas de saúde física, emocional e espiritual (ATEŞ G, et al., 2018; DIONNE-ODOM JN, et al., 2016).

É notável que tais problemas estão atrelados ao comprometimento de sua saúde mental, recorrentes da sobrecarga do cuidado. Portanto, torna-se cada vez mais necessário que os CPs possam auxilia-los da amenização destes efeitos. Contudo, a atenção ainda encontra-se voltada apenas para o paciente em CP em fim de vida (YOO SH, et al., 2018).

Em contrapartida, é importante ressaltar que os cuidadores são importantíssimos para o bem-estar de seus familiares adoecidos pelo câncer durante todo o curso e desfecho da doença, visto toda a ênfase de tempo e motivação empregadas aos cuidados realizados para o adoecido. Embora os objetivos dos cuidados sejam multifacetados, por trás de tais motivações também existe 0 fardo que afeta o bem-estar dos cuidadores.

O adoecimento de um ente do núcleo familiar resulta na necessidade da reestruturação deste, para que novos papéis sejam assumidos, influenciando nas motivações e encargos para a saúde, oriundos do cuidar 
de um membro da família moribundo (NISSEN KG, et al., 2016). Logo, são necessárias pesquisas que viabilizem a conscientização sobre preocupações, necessidades e estresse dos CFs para o fornecimento de informações sobre os cuidados de suporte, bem como, para que ocorra a integração destes no planejamento dos cuidados, reafirmando as características importantes dos cuidados paliativos (ULLRICH A, et al., 2017).

Dessa forma, não é somente a intensidade do evento que contribui para a intensificação do estresse no cuidador, mas como este o percebe, de maneira que, se as formas de enfrentamento não forem suficientemente capazes de diminui-los, seu bem-estar estará ameaçado. Assim, este estudo tem como objetivo identificar os principais fatores de estresse do familiar cuidador de adoecidos em cuidados paliativos oncológicos domiciliares.

\section{MÉTODOS}

Trata-se de uma pesquisa descritiva com abordagem qualitativa, realizada com 10 familiares cuidadores de adoecidos pelo câncer em cuidados paliativos oncológicos domiciliares, vinculados ao Serviço de Assistência Domiciliar de um hospital no estado do Pará, o qual se trata de uma instituição de referência no tratamento do câncer no estado (HOL, 2019).

Configuraram-se como critérios de inclusão: familiares cuidadores de adoecidos em cuidados paliativos oncológicos domiciliares, cadastrado no Serviço de Assistência Domiciliar (SAD) do referido hospital maiores de 18 anos; residindo na cidade de Belém e região metropolitana. Foram excluídos do estudo: cuidadores cujo familiar adoecido encontrava-se internado na instituição hospitalar e cuidadores contratados que não pertenciam à família.

No início da coleta de dados, havia cadastrado no SAD do hospital, um total de 15 adoecidos em cuidados paliativos oncológicos, recebendo atendimento da equipe domiciliar, cada um com um familiar cuidador autodeclarado. Primeiramente, todos foram admitidos na pesquisa, conforme os critérios de inclusão e exclusão, porém, antes do primeiro contato com os mesmos, cinco de seus adoecidos foram a óbito, devendo seus familiares cuidadores serem retirados da pesquisa, cuja amostra final resultou em 10 familiares cuidadores.

Para a construção do estudo, foi realizada observação das visitas domiciliares desenvolvida pela equipe de cuidados paliativos do HOL, de segunda à quinta-feira, das $9 \mathrm{~h}$ às $12 \mathrm{~h}$, nas residências dos adoecidos, com agendamento de retorno para a realização de entrevista semiestruturada com os familiares cuidadores destes, as quais foram gravadas e transcritas na íntegra.

Os dados foram coletados no primeiro semestre de 2016. Para a coleta, a fim de subsidiar a entrevista semiestruturada, foi elaborado um roteiro de questões abertas aos familiares cuidadores para identificar os principais fatores causadores de estresse dos mesmos, a fim de descrever as estratégias utilizadas por esses familiares no enfrentamento do estresse desencadeado pelo cuidado. Este estudo foi submetido à análise do Comitê de Ética em Pesquisa do Instituto de Ciências da Saúde da Universidade Federal do Pará (CEP/ICS/UFPA) e aprovado sob o parecer 518.778.

\section{RESULTADOS}

Os familiares cuidadores foram identificados pela letra $S$ de "sujeitos" e por números, em sequência, mantendo-se a ordem de realização das entrevistas: S1, S2, S3, S4, S5, S6, S7, S8, S9 e S10. Dos informantes, todos eram do sexo feminino, sendo 8 filhas, 1 esposa e 1 irmã, com idade entre 18 e 61 anos, cuja metade era solteira e a outra casada. A escolaridade variou de ensino fundamental incompleto à nível superior, com renda entre 1 e 8 salários mínimos, subsidiando de 2 a 6 membros na residência.

A partir da análise dos dados, emergiram duas categorias temáticas e suas respectivas subcategorias, denominadas: Estressores do cuidado: do amor à dor, com as subcategorias: O cuidar como sinônimo de amor e compromisso; e Estressores do cuidado: adoecimento físico e psicológico, sendo a segunda categoria: Superando os limites do estresse: estratégias de enfrentamento. A primeira expressa atitudes de amor, desvelo, solicitude e atenção ao adoecido. A segunda, de preocupação, inquietação e responsabilidade, pois o cuidador sente-se envolvido e ligado ao familiar. 


\section{Estressores do cuidado: do amor à dor}

Por meio dos relatos das informantes, verificou-se que o ato de cuidar possui uma dualidade coberta de significados pessoais, evoluindo para dois extremos interligados intimamente.

O cuidado é visto como sinônimo de amor e compromisso ao mesmo tempo em que se manifesta carregado de estressores provenientes da ação de cuidar, cujo adoecimento físico e psicológico é a consequência mais presentes no papel desenvolvido pelo cuidador.

O cuidar como sinônimo de amor e compromisso Quando questionadas sobre o ato de cuidar de seu familiar adoecido, dos relatos das cuidadoras, foi possível depreender significados que perpassaram por duas palavras-chave: amor e compromisso, onde o amor esteve ligado aos sentimentos e a palavra compromisso, principalmente relacionada ao vínculo familiar. O cuidado como sinônimo de amor está relacionado a sentimentos como carinho (S1), proteção (S4), pertencimento (S6) e necessidade de fazer o outro sentir-se bem, além de realiza-lo como forma de retribuição (S8), como se apresentam as falas em seguida.

"Eu demonstro meu amor por ele quando cuido com carinho. Eu beijo, abraço, cheiro e fico muito feliz quando ele ri pra mim." (S1)

"O amor que eu tenho por ela 'faz eu fazer' qualquer coisa. Eu protejo ela o tempo todo, porque qualquer coisa pode piorar o estado dela. Não deixo qualquer pessoa entrar aqui pra visitar ela, porque tem gente que só vem pra falar besteira." (S4)

"Eu amo muito a minha mãe. Quando ela precisa internar, eu não gosto que outra pessoa fique com ela. Eu fico porque sei que ninguém vai cuidar dela como eu cuido. É minha mãe, então eu não vou largar na mão de qualquer pessoa, que nem muitos por aí fazem." (S6)

"Eu faço de tudo pra ela ficar bem. Compro as coisas que ela gosta, assisto novela com ela, converso e sempre tento distraí-la, porque eu amo tanto ela sabe, que eu não gosto de ver ela triste. Além disso ela é a minha mãe, e isso é o mínimo que eu posso fazer por ela." (S8)

As falas das cuidadoras representam o potencial humano para cuidar do outro, manifestando sentimentos de amor, vínculo familiar e compromisso de vida. Tal comportamento perpassa por conceitos em que 0 ato de cuidar é marcado por estas prerrogativas.

\section{Estressores do cuidado: adoecimento físico e psicológico}

As cuidadoras, diante do processo de cuidar, mesmo que de forma espontânea e motivada por sentimentos de amor e compromisso, não conseguiram esconder o estresse que as acomete, direta ou indiretamente.

Os estressores do cuidado oriundos da sobrecarga física e emocional levaram-nas à consequências como o adoecimento físico e psicológico. Desequilíbrios fisiológicos oriundos da sobrecarga física como: dores musculares (S1), baixa da imunidade (S5) e astenia (S9), associados, principalmente à má alimentação e sono e repouso prejudicado, foram os mais evidentes, conforme as falas.

"Sinto dores no corpo todos os dias. Dói o músculo da perna, da costa, do braço; meus pés no final do dia estão acabados. Eu mesma tento fazer uma 'massagenzinha', mas no outro dia vai doer do mesmo jeito. Como eu tenho que carregar ela quase sempre, fico acabada, fora que eu não durmo bem, porque me preocupo que ela passe mal à noite." (S1)

'Fui 'no' médico mês passado e ele disse que eu 'tava' com baixa resistência; passou uma vitamina e me disse que é por causa do estresse, porque eu não durmo e não como direito." (S5)

"Antes eu gostava de sentar pra comer, mas agora nem tenho fome. As vezes só belisco a comida, aí no fim do dia me sinto tão fraca e cansada." (S9). 
Além do físico, o psicológico é evidentemente afetado na maioria das entrevistadas, pois relatam terem perdido o prazer em realizar outras atividades que não estejam ligadas ao familiar adoecido e, consequentemente, surgem sentimentos como tristeza e solidão (S2 e S5).

"Eu não sinto vontade de sair como eu saía antes dela adoecer. Antes eu me divertia muito e sempre tirava um final de semana pra ir ao cinema com as meninas, mas agora não tenho mais vontade. Prefiro ficar aqui cuidando dela. Não sei se é por isso que eu sinto tanta tristeza, além de ver a mamãe assim." (S2)

"As minhas amigas até me convidam pra sair de vez em quando, mas eu não sinto mais vontade de ir. Uma vez até fui, mas fiquei agoniada e já queria voltar pra saber da mamãe. Mas eu sei que isso adoece a minha mente, porque às vezes eu fico triste do nada e me sinto sozinha." (S5)

O adoecimento psicológico desencadeado pelo estresse do cuidado é oriundo da priorização do doente em detrimento de suas necessidades. Cuidar tornou-se prioridade na vida das mesmas, e por isso abdicam de momentos de lazer para a exclusiva dispensação do cuidado ao adoecido. Além disso, duas cuidadoras relataram chorar excessivamente devido à condição do familiar adoecido e o medo que ainda existe de enfrentar a morte do mesmo (S7 e S10)

"Eu não queria que ela tivesse ficado desse jeito. Eu choro muito de ver o estado dela. Eu tenho chorado muito fácil esses dias. Queria muito que ela melhorasse, pelo menos um pouco mais. Eu sei que ela vai precisar partir um dia, mas eu ainda tenho medo de perder ela... (chorou)." (S7)

"Tu não faz ideia do quanto eu tenho chorado. Meu olho vive inchado. Só de pensar que a qualquer momento eu posso perder ele, me derramo. Eu sei que ele tá mais perto de ir embora, mas eu não sei o que vai ser de mim depois disso (chorou)." (S10)

\section{Superando os limites do estresse: estratégias de enfrentamento}

Mesmo diante de toda a carga de estresse física e psicológica que vive o familiar cuidador, os estressores do cuidado podem ser enfrentados de forma eficaz, quando se consegue amenizar as situações de estresse por meio da utilização de estratégias, sejam elas construídas de forma pessoal, orientadas por profissionais de saúde ou aprendidas de outra forma. Mediante a isto, parte das cuidadoras familiares procuram meios de enfrentar o estresse e para isso utilizam estratégias diversas. Para não adoecer devido à má alimentação, procuram suprir nos intervalos comendo frutas e ingerindo líquidos (S4). O sono é melhorado quando pedem ajuda de outra pessoa da família para dar suporte durante a noite (S6), além de algumas delas procurarem ir às consultas e exames regularmente (S1 e $\mathrm{S} 3$ ).

"Se hoje eu não consegui almoçar direito como deveria, amanhã eu já não vou vacilar, porque eu sei que eu posso adoecer e aí não vou conseguir cuidar direito dela. Eu sempre procuro comer frutas e tomo bastante água também." (S4)

"Como eu sei que se eu ficar sozinha com ela de noite eu não vou dormir nadinha, peço para o meu sobrinho dormir aqui pelo menos umas três vezes por semana, aí ele já me ajuda com ela. Quando ele tá aqui eu sempre durmo melhor." (S6)

"Eu sempre vou 'nas minhas consultas', eu não posso vacilar por causa da diabetes." (S1).

"Sim, eu vou às consultas e meus exames estão todos em dia. Eu preciso cuidar de mim um pouquinho." (S3)

Apesar de algumas cuidadoras apresentarem dificuldades em relação ao medo de não suportarem a morte de seu familiar adoecido, outras conseguiram superar esta etapa antecipadamente através de uma estratégia de enfrentamento, onde passaram a visualizar a morte como uma forma de aliviar o sofrimento de seu ente e aceita-la como um processo natural da vida, a exemplo da fala da cuidadora 3. 
"Eu faço de tudo para que ela se sinta bem, mas também sei que ela sofre muito. Já passamos por tanta coisa... e eu sei que o dia que ela for embora, estará fechando um ciclo e nunca mais sofrerá." (S3)

Mesmo com todas as estratégias utilizadas por algumas cuidadoras para o enfrentamento do estresse, outras conseguem e não procuram meios de fazê-lo. Duas entrevistadas alegam que além de não conseguirem superar os limites do estresse, não recebem orientação de ninguém (S2 e S10).

"Eu me estresso muito rápido, fico triste, choro. Me aborreço muito também, mas tento não passar isso pra ela, porque ela não merece meu estresse. Às vezes eu quero conversar com alguém, mas eu até evito. Os profissionais que vem aqui, até conversam um pouco, mas não dão as dicas que eu preciso." (S2)

"Não 'tô' conseguindo enfrentar isso, me sinto sozinha, tenho andado um pouco estressada, mas ninguém me ajuda." (S10)

\section{DISCUSSÃO}

A aproximação do momento da morte pode gerar no cuidador angústia, tristeza e ansiedade, sentimentos inerentes a este momento complexo, em que a experiência do cuidar é mediada pelo tempo e intensidade do cuidado, o qual passa a ser entendido como atitude de gentileza e consideração, inerentes ao senso de responsabilidade pelo outro, como atitude moral perante ao familiar. Os cuidadores cônjuges podem perceber o papel de cuidador como parte esperada do relacionamento conjugal (DIONNE-ODOM JN, et al., 2016; LIMA CP e MACHADO MA, 2018).

Em quase todos os artigos pesquisados em estudo, os cuidadores familiares eram pessoas do sexo feminino, as quais não poderiam recursa-se ao papel, independente da razão, por correr o risco de estigmatização social (ABREU AISCS e COSTA JÚNIOR ÁL, 2018).

No domicilio, os cuidadores são os alicerces que sustentam fisicamente, emocionalmente, espiritualmente e financeiramente o adoecido e/ou outros membros da família, assumindo involuntariamente múltiplas funções em consequência do contexto, abdicando de sua própria vida para cuidar. Eles redimensionam suas vidas para lidar com o adoecimento de seu familiar e as implicações que a doença pode causar (MENEGUIN S e RIBEIRO R, 2016; OLIVEIRA MBP, et al., 2017).

Por isso, suprir tais necessidades contribui com o estresse do cuidado estando ligadas à informação sobre o cuidado e o seu planejamento; apoio às dificuldades enfrentadas diante do medo da morte à medida que o status físico ou psicológico do paciente diminui e preparação para a morte do paciente e seu próprio luto. Assim, pode-se enquadra-las nas necessidades relacionadas ao bem-estar do paciente, transferência de informações, problemas práticos de prestação de cuidados e suporte emocional. Os CFs necessitam de um reforço físico, social, emocional e espiritual, além de informações precisas para que possam sentirem-se completamente seguros nesta nova realidade (OLIVEIRA MBP, et al., 2017; ULLRICH A, et al., 2017).

Todavia, poucas intervenções tendem à saúde mental dos cuidadores, e quando o fazem, são direcionadas para atendimento das necessidades do paciente, existindo um foco secundário no cuidador, embora, os objetivos do CP partam também para atender às necessidades destes, aliviando seu estresse (JACOBS JM, et al., 2017).Assim, a equipe de CP, sobretudo a enfermagem, precisa fornecer apoio individualizado aos cuidadores sobre as tarefas de cuidar e como lidar com a luta no percurso do cuidado. Tais informações melhorariam sua segurança no desempenho das atividades e beneficiariam seu bem-estar, visto que estudos demonstram que os cuidadores apresentaram humor deprimido e carga de estresse diminuídos (DIONNE-ODOM JN, et al., 2016).

Pesquisas mostram que apesar do esgotamento físico e emocional, os cuidadores expressavam o desejo de permanecer ao lado de seu familiar até o fim. Mesmo que consigam identificar o lado positivo relacionado à sua função com o adoecido, ainda sim, cuidar de alguém em fim de vida é estressante e se não tiveram um suporte que atenda às suas necessidades, inclusive durante o luto, sua sintomatologia psicopatológica será mais acentuada (DELALIBERA M, et al., 2018; LIMA CP e MACHADO MA, 2018). 
Concomitante a isto, estudo ressalta que o efeito negativo do cuidar pode ser contraposto pelo suporte de outras pessoas e com a facilitação do acesso aos recursos sociais e profissionais especializados, dado que os cuidadores relatam falta de preparação e orientação mínima fornecida pelo sistema de saúde (DELALIBERA M, et al., 2018; JACOBS JM, et al., 2017).

Outro estudo frisa a importância de se reconhecer os CFs como 'unidade de cuidado', para além dos profissionais, e parceiros no cuidado, melhorando o suporte ofertado e viabilizando seu conhecimento sobre o que está disponível a ele (ATEŞ G, et al., 2018). Os serviços de assistência domiciliar precisam garantir a continuidade do atendimento aos pacientes e capacitar o cuidador na família, ensinando-lhes métodos simples e econômicos de cuidar dos pacientes, principalmente em locais com poucos recursos, onde o acesso aos cuidados especializados é difícil (PHILIP RR, et al., 2018).

Nos poucos estudos sobre o uso de serviços de apoio por cuidadores familiares de câncer, o uso geral é baixo, logo são necessárias mais pesquisas para que se possa compreender mais os pontos fortes e fracos de modelos de atendimento domiciliar que atendam às necessidades dos cuidadores e as experiências diante os estressores do cuidado (DIONNE-ODOM JN, et al., 2016; PHILIP RR, et al., 2018).

Por conseguinte, é preciso que se tenha o reconhecimento do estresse dos CFs pelos profissionais de saúde para conduzir melhor o gerenciamento bem-sucedido dos sintomas, bem como rastreio do estresse, fornecimento de informações adequadas e o planejamento adequado dos cuidados como características de maior qualidade de atendimento (ULLRICH A, et al., 2017).

Para reduzir as tenções dos cuidadores, são necessários programas estruturados de cuidados paliativos que ofereçam apoio psicossocial às famílias dos pacientes, além dos cuidados biológicos. Nesse contexto, a enfermagem precisa viabilizar a construção do vínculo, perpassando o cuidado tanto pelo paciente quanto à família (PHILIP RR, et al., 2018; REIS EB, et al., 2019). Portanto, é necessária aproximação com a temática para que ocorram intervenções efetivas em apoio aos cuidadores. Para tal, as competências de enfermagem são importantes em todo o processo de doença do câncer, se estendendo para além do tratamento curativo (CARNEIRO CPF, et al., 2019). Como limitações de estudo, houve a indisponibilidade de tempo dos cuidadores para a realização da entrevista; dificuldade de reagendamento das mesmas por estes; ausência do sujeito durante a visita domiciliar e posterior entrevista; internação e/ou óbito dos pacientes em cuidados paliativos, inviabilizando a entrevista com seu familiar cuidador.

\section{CONCLUSÃO}

Constamos, neste estudo, que o cuidado é desenvolvido pelas familiares cuidadoras com responsabilidade, amor e compromisso, de forma que procuram garantir ao adoecido, dias melhores. Os principais estressores do cuidado identificados, estão relacionados ao adoecimento físico e abalo psicológico. Entretanto, algumas delas tem buscado superar os limites do estresse através de diversas estratégias de enfrentamento. Contudo, ainda foram identificadas cuidadoras que não conseguem desenvolver nem elaborar estratégias que as permitam superar o estresse desencadeado pelo cuidado, pois não recebem orientações. Desta forma, a enfermagem deve atuar diretamente junto a estes cuidadores, oferecendo suporte adequado e orientações eficientes que os permitam construir para si mesmos, estratégias de enfrentamento diante dos estressores do cuidado, a fim de que consigam cuidar de seu familiar adoecido e realizar seu autocuidado.

\section{Agradecimentos e financiamento.}

Agradecimentos ao CNPq pela concessão de auxilio de no 156596/2014-8 por meio do Programa Institucional de Bolsas de Iniciação Científica (PIBIC).

\section{REFERÊNCIAS}

1. ABREU AISCS, COSTA JÚNIOR ÁL. Sobrecarga do cuidador familiar de paciente oncológico e a enfermagem. Rev enferm UFPE on line, 2018; 12(4): 976-86. 
2. ATES G, et al. "Never at ease" - family carers within integrated palliative care: a multinational, mixed method study. BMC Palliat Care, 2018; 17(1): 39.

3. BARDIN L. Análise de conteúdo. Lisboa, Portugal: Edições 70; 2011.

4. CARNEIRO CPF, et al. O Papel do enfermeiro frente ao câncer de colo uterino. Revista Eletrônica Acervo Saúde, 2019; (35): e1362.

5. DELALIBERA M, et al. Circunstâncias e consequências do cuidar: caracterização do cuidador familiar em cuidados paliativos. Ciênc. saúde coletiva, 2018; 23(4): 1105-1117.

6. DIONNE-ODOM JN, et al. Associations between advanced cancer patients' survival and family caregiver presence and burden. Cancer Med, 2016; 5(5): 853-862.

7. HOSPITAL OPHIR LOYOLA (HOL). Missão, visão e valores. Disponível em: http://www.ophirloyola.pa.gov.br/institucional/missao-visao-valores/. Acesso em: 10 jun. 2019.

8. INSTITUTO NACIONAL DE CÂNCER (INCA). Estimativa 2018: incidência de câncer no Brasil. Rio de Janeiro: INCA, $2017 \mathrm{~b} ; 128 \mathrm{p}$.

9. JACOBS JM, et al. Distress is Interdependent in Patients and Caregivers with Newly Diagnosed Incurable Cancers. Ann Behav Med, 2017; 51(4): 519-531.

10. LIMA CP, MACHADO MA. Cuidadores Principais Ante a Experiência da Morte: Seus Sentidos e Significados. Psicologia: Ciência e Profissão, 2018; 38(1): 88-101.

11. MENEGUIN S, RIBEIRO R. Dificuldades de cuidadores de pacientes em cuidados paliativos na estratégia da saúde da família. Texto contexto - enferm, 2016; 25(1): e3360014. Disponível em: http://www.scielo.br/scielo.php?script=sci_arttext\&pid=S0104-07072016000100312\&lng=en. Acesso em: 18 nov. 2019.

12. NISSEN KG, et al. Family Relationships and Psychosocial Dysfunction Among Family Caregivers of Patients With Advanced Cancer. J Pain Symptom Manage, 2016; 52(6): 841-849.

13. OLIVEIRA MBP, et al. Atendimento domiciliar oncológico: percepção de familiares/cuidadores sobre cuidados paliativos. Esc. Anna Nery, 2017; 21(2): e20170030. Disponível em: http://www.scielo.br/scielo.php?script=sci_arttext\&pid =S1414-81452017000200202\&lng=en. Acesso em: 18 nov. 2019.

14. PHILIP RR, et al. Twenty years of home-based palliative care in Malappuram, Kerala, India: a descriptive study of patients and their care-givers. BMC Palliat Care, 2018; 17(1): 26.

15. REIS EB, et al. "Se tem batimento, tem vida": vivências em torno da hospitalização na visão de familiares de pacientes internados no CTI. Revista Eletrônica Acervo Saúde, 2019; 11(16): e1175.

16. ULLRICH A, et al. Quality of life, psychological burden, needs, and satisfaction during specialized inpatient palliative care in family caregivers of advanced cancer patients. BMC Palliat Care, 2017; 16(1):31.

17. WORLD HEALTH ORGANIZATION (WHO). Global Health Observatory. Geneva: World Health Organization; 2019. Disponível em: https://gco.iarc.fr/today/data/factsheets/populations/900-world-fact-sheets.pdf. Acesso em: 15 nov. 2019.

18. YOO SH, et al. Attitudes toward early palliative care in cancer patients and caregivers: a Korean nationwide survey. Cancer Med, 2018; 7(5): 1784-1793. 